\title{
FARELO DE MELANCIA FORRAGEIRA EM DIETAS PARA OVINOS CONSUMO E DIGESTIBILIDADE DOS NUTRIENTES
}

\author{
Raimundo Luiz Nunes Vaz da Silva ${ }^{2}$, Gherman Garcia Leal de Araújo ${ }^{3}$, Eliomar Pereira do Socorro ${ }^{4}$, \\ Décio Hamilton de Souza Santos ${ }^{2}$, Vanderlito dos Santos Costa ${ }^{5}$ \\ 2 Professor da EAFCATU - BA. Email: raimundoluizvaz@eafcatu.gov.br \\ 3 Pesquisador Embrapa Semi-Árido \\ 4 Professor do Depto Prod. Animal - MEV/UFBA \\ 5 Técnico agrícola da EAFCATU - BA
}

Resumo: Com o objetivo de avaliar o farelo de melancia forrageira (Citrullus lanatus cv. citroides) (FMF) em dietas à base de feno de guandu (Cajanus cajan) (FG), foi realizado um ensaio de digestibilidade em ovinos. Para testar cinco níveis de FMF (20, 35, 50,65 e 80\%) foram utilizados 20 cordeiros com idade média de seis meses e peso vivo médio de $11,2 \mathrm{~kg}( \pm 1,2)$. O experimento constou de vinte dias de adaptação e cinco dias de coleta total de sobras e de fezes. Foi determinada a composição bromatológica dos alimentos e os consumos de matéria seca (MS), matéria orgânica (MO), proteína bruta (PB), extrato etéreo (EE) e suas digestibilidades foram mensuradas. Os consumos de MS, MO e PB, apresentaram um comportamento quadrático $(\mathrm{P}<0,05)$ em função dos níveis de $\mathrm{FMF}$. $\mathrm{O}$ consumo de extrato etéreo não foi alterado $(\mathrm{P}>0,05)$. Os coeficientes de digestibilidade da MS (58\%), PB (69\%) e EE $(85 \%)$ não foram influenciados significativamente pelo nível de farelo de melancia forrageira. A digestibilidade da MO (54 a 62\%) variou linear e positivamente. As dietas experimentais proporcionaram consumo de matéria seca que atendeu a exigência dos animais. Os coeficientes de digestibilidade observados foram satisfatórios.

Palavras-chave: nutrição, aspectos digestivos, alimentos, cordeiros

\begin{abstract}
In order to evaluate the inclusion of watermelon-forage (Citrullus lanatus var. Citroides) meal (WFM) in basal diet of pigeon pea (Cajanus cajan) hay (PPH), a digestibility trial in sheep was carried out for testing five levels of WFM $(20,35,50,65$ and $80 \%)$. Twenty lambs with an average age of six months and live weight of $11.2 \mathrm{~kg}( \pm 1.2)$ were used. The experimental period was twenty days for adaptation and five days for total collection of refuses and feces. Chemical composition of diet ingredients was determined and the intakes of dry matter (DM), organic matter (OM), crude protein (CP), ether extract (EE) and their digestibilities were measured. The intakes of DM, OM and CP showed a quadratic behavior $(\mathrm{P}<0.05)$ according to the levels of WFM. Intake of ether extract was not changed $(\mathrm{P}>$ $0.05)$. The coefficients of digestibility of DM (58\%), OM (69\%) and EE (85\%) were not significantly influenced by the level of watermelon-forage meal. The digestibility of OM (54 to 62\%), ranged linear and positively. The experimental diets provided dry matter intake enough to attend the animal requirements. The coefficients of digestibility observed were satisfactory.
\end{abstract}

Keywords: nutrition, digestive aspects, foods, lambs

\section{Introdução}

A ovinocaprinocultura é um importante componente sócio-econômico para manutenção das famílias Nordestinas. A produção animal é um meio importante de sustentação da população rural pelo aporte de renda e proteína alimentar. Atualmente, busca-se opções alimentares para viabilizar a produção animal no semi-árido. Entre as espécies nativas que vêm sendo estudadas para alimentação animal incluem-se a maniçoba, o angico, a catingueira, o juazeiro e as cactáceas, como o facheiro e mandacaru (Cândido, 2005). Outras espécies introduzidas são apontadas como forrageiras, a exemplo da palma, as Stylosanthes capitata e macrocephala, a leucena, a gliricídia e o guandu taipeiro (Gomide et al., 2006). Contudo, são escassos os trabalhos sobre a utilização da melancia forrageira na dieta de ruminantes em bases cientificamente fundamentadas na literatura. A melancia forrageira, conhecida também como melancia de porco, do mato, de cavalo ou caiana, é de notável resistência à seca, fácil cultivo e bem aceita pelos ruminantes. Entretanto, aspectos relacionados à sua utilização digestiva, como potencial de consumo e coeficientes de digestibilidade estão ainda pouco esclarecidos.

Este estudo avaliou a inclusão de farelo de melancia forrageira (FMF) em dietas à base de feno de guandu (FG) para ovinos, com base no consumo e na digestibilidade dos nutrientes. 


\section{Material e Métodos}

O experimento foi realizado na estação experimental da Embrapa, Semi-Árido, Petrolina (PE), durante os meses de setembro e outubro de 2001. O ensaio teve duração de vinte e cinco dias, sendo vinte de adaptação e cinco dias de coleta total de fezes e sobras. Foram utilizados 20 cordeiros SRD, nativos, com idade média de seis meses e peso vivo médio de $11,2 \mathrm{~kg}( \pm 1,2)$. Os animais foram alojados em gaiolas de metabolismoOs alimentos utilizados foram o farelo de melancia forrageira (C. lanatus cv. citroides) e o feno de guandu (C. cajan). O FMF foi obtido a partir da passagem do fruto integral "in natura" numa máquina de fazer raspas de mandioca e o material resultante espalhado em camadas sobre terreiro cimentado para desidratação ao sol durante 36 horas. Em seguida, o material desidratado foi desintegrado em moinho utilizando-se peneira com malha de $10 \mathrm{~mm}$ de diâmetro. O FG foi preparado ao sol e picado em partículas de aproximadamente 4 a $5 \mathrm{~cm}$ em picadeira motorizada. Água e mistura mineral completa foram fornecidos à vontade aos animais. As dietas foram fornecidas duas vezes ao dia, às $8 \mathrm{~h}$, e às $15 \mathrm{~h}$ e $30 \mathrm{~min}$ da tarde, ajustando-se a sobra diária para $20 \%$ em relação à dieta oferecida, por animal. Foram feitas anotações diárias da quantidade de ração fornecida e das sobras de cada animal, além de amostragem semanal do concentrado, volumoso e sobras para análises posteriores. Foram estudados cinco tratamentos referentes aos níveis de 20,35, 50, 65 e 80\% de inclusão do farelo de melancia forrageira (FMF) na dieta de feno de guandu. Os consumos foram aferidos e as digestibilidades foram calculadas utilizando a fórmula abaixo Schneider \& Flatt (1975).

$\mathrm{CD}=[(\underline{\text { Oferecido }- \text { rejeitado }) \text { - excretado }}] \times 100$

(Oferecido - Rejeitado)

O delineamento experimental foi inteiramente casualizado, com cinco tratamentos e quatro repetições e os dados foram analisados utilizando-se os procedimentos GLM e REG do SAS (Statistical Analysis System, (1996).

\section{Resultados e Discussão}

Os consumos diários das dietas experimentais, expressos em $\mathrm{g} / \mathrm{dia}$ e $\mathrm{g} / \mathrm{kg}^{0,75} \mathrm{e}$ os pontos de máximo consumo (PMC) encontram-se na Tabela 1. Os dados demonstraram que os consumos de MS, MO, PB, apresentaram comportamento quadrático $(\mathrm{P}<0,05)$ em relação ao nível de inclusão do farelo de melancia forrageira (FMF) nas dietas. Os consumos de MS foram estatisticamente semelhantes entre si nos níveis intermediários de inclusão de FMF (35 a 65\%) e mais elevados em relação àqueles observados nos níveis extremos (20\% e 80\%). A ingestão de MS das dietas mais consumidas atendeu à exigência de $500,0 \mathrm{~g}$ de MS/dia do NRC (1985). Nos pontos de máximo consumo de MS equivalentes aos níveis de inclusão de $66 \%, 65,2$ e $50 \%$ foi mantida essa tendência, sendo a exigência atendida em $100 \%$ e superada em $8,4 \%$. Os consumos de MO foram máximos ao nível médio de $66 \%$ de inclusão de FMF, enquanto a ingestão máxima de PB foi observada ao nível médio de 69\% de FMF. O teor médio de PB das dietas $(18,61 \%)$, proporcionou um consumo de $81,0 \mathrm{~g}$ de $\mathrm{PB} / \mathrm{dia}$, que representou $95 \%$ da exigência diária contudo, no PMC essa exigência foi superada em 13\%. O consumo de EE não foi afetado pelos níveis de incorporação de FMF. Já o consumo médio de EE das dietas testadas $\left(44,38 \mathrm{~g} / \mathrm{dia}\right.$ e $6,15 \mathrm{~g} / \mathrm{kg}^{0,75}$ ) foi superior ao verificado por Gonzaga Neto et al. (2001) $\left(21,7 \mathrm{~g} / \mathrm{dia}\right.$ e $\left.1,97 \mathrm{~g} / \mathrm{kg}^{0,75}\right)$ para dietas a base de feno de catingueira. De fato, os teores de extrato etéreo das dietas neste trabalho foram bastante superiores aqueles das dietas contendo feno de catingueira, indicando em dietas compostas por FMF tolerância a níveis mais elevados de EE.

Tabela 1. Consumos de nutrientes em função dos níveis de farelo de melancia forrageira (FMF) expressos $\mathrm{em} \mathrm{g} / \mathrm{dia}$ e $\mathrm{g} / \mathrm{kg}^{0,75}$

\begin{tabular}{|c|c|c|c|c|c|c|c|c|c|}
\hline FMF & $20 \%$ & $35 \%$ & $50 \%$ & $65 \%$ & $80 \%$ & Equação de regressão & PMC & Nível & $\mathrm{R}^{2}$ \\
\hline $\begin{array}{l}\text { MS } \\
g / d i a\end{array}$ & 422,0 & 501,0 & 525,0 & 533,0 & 371,0 & $\begin{array}{l}Y=200,05+ \\
220,74 \mathrm{FMF}-35,60\end{array}$ & 542,0 & 66,0 & 0,91 \\
\hline $\begin{array}{l}\mathrm{MS} \\
\mathrm{g} / \mathrm{kg}^{0,75}\end{array}$ & 64,76 & 72,67 & 78,02 & 78,42 & 60,33 & $\begin{array}{l}\mathrm{Y}=35,05+1,77 \mathrm{FMF}- \\
0,0179 \mathrm{FMF}^{2}\end{array}$ & 78,7 & 65,2 & 0,90 \\
\hline $\begin{array}{l}\text { MO } \\
\text { g/dia }\end{array}$ & 364,0 & 461,0 & 461,0 & 471,0 & 328,0 & $\begin{array}{l}Y=163,98+207,46 \\
F M F-33,56 \mathrm{FMF}^{2}\end{array}$ & 484,9 & 67,0 & 0,92 \\
\hline $\begin{array}{l}\mathrm{MO} \\
\mathrm{g} / \mathrm{kg}^{0,75}\end{array}$ & 55,78 & 66,63 & 68,52 & 69,05 & 53,42 & $\begin{array}{l}\mathrm{Y}=28,08+1,71 \mathrm{FMF}- \\
0,0173 \mathrm{FMF}^{2}\end{array}$ & 70,3 & 66,0 & 0,94 \\
\hline PB g/dia & 73,0 & 89,0 & 91,0 & 94,0 & 60,0 & $\begin{array}{l}\mathrm{Y}=21,69+46,41 \mathrm{FMF}- \\
7,21 \mathrm{FMF}^{2}\end{array}$ & 96,4 & 67,0 & 0,95 \\
\hline $\begin{array}{l}\mathrm{PB} \\
\mathrm{g} / \mathrm{kg}^{0,75}\end{array}$ & 11,19 & 13,10 & 13,52 & 13,65 & 9,74 & $\begin{array}{l}Y=5,62+0,35 \mathrm{FMF}- \\
0,0038 \mathrm{FMF}^{2}\end{array}$ & 13,7 & 65,1 & 0,97 \\
\hline EE g/dia & 35,0 & 48,0 & 51,0 & 52,6 & 35,0 & $\mathrm{Y}=44,38$ & - & - & - \\
\hline
\end{tabular}




\begin{tabular}{lllllllll}
\hline $\begin{array}{l}\mathrm{EE} \\
\mathrm{g} / \mathrm{kg}^{0,75}\end{array}$ & 5,40 & 7,17 & 6,68 & 6,43 & 5,09 & $\mathrm{Y}=6,15$ & - & - \\
\hline
\end{tabular}

Os coeficientes de digestibilidade da MS, MO, PB, EE, são apresentados na tabela 2. Os níveis do FMF não influenciaram a digestibilidade da MS, PB e EE. Com o aumento do nível de FMF na dieta, o coeficiente de digestibilidade (CD) da MO apresentou um comportamento linear crescente, 54 a $62 \%$. Os coeficientes de digestibilidade da matéria seca (MS) situaram entre 58,76 e 62,84\%, valores assemelhados aos obtidos por Woodward \& Reed et al. (1995), com A. brevispica, S. sesban e V. dasycarpa. Já os valores dos coeficientes de digestibilidade da matéria orgânica (MO) medidos neste trabalho são inferiores aos encontrados por Krishnamoorthy et al. (1995), para Gliricidia maculata (66,60\%), mas próximos aos valores encontrados com Leucaena leucocephala (62,0\%). Os coeficientes de digestibilidade da MS, PB e EE não demonstraram efeitos associativos, similarmente aos consumos. Por outro lado, o coeficientes de digestibilidade da $\mathrm{MO}$, foi linearmente crescente, influenciado pelo nível de incorporação do FMF, segundo a seguinte equação: $\mathrm{Y}=63,09+1,95 \mathrm{FMF}, \mathrm{R}^{2}=0,86$.

Tabela 4. Coeficientes de digestibilidade (CD) dos nutrientes em função dos níveis de farelo de melancia forrageira nas dietas

\begin{tabular}{|c|c|c|c|c|c|c|c|}
\hline \multirow{2}{*}{$\mathrm{CD} \%$} & \multicolumn{5}{|c|}{ Níveis de Farelo de Melancia Forrageira (F) } & \multirow[b]{2}{*}{$\begin{array}{l}\text { Equação de } \\
\text { regressão }\end{array}$} & \multirow[b]{2}{*}{$\mathrm{R}^{2}$} \\
\hline & $20 \%$ & $35 \%$ & $50 \%$ & $65 \%$ & $80 \%$ & & \\
\hline MS & 56 & 55 & 58 & 60 & 59 & $\mathrm{Y}=58,0$ & - \\
\hline MO & 54 & 55 & 55 & 59 & 62 & $\begin{array}{l}Y=63,09+1,95 \\
F M F\end{array}$ & 0,86 \\
\hline PB & 70 & 66 & 68 & 73 & 67 & $\mathrm{Y}=69,0$ & - \\
\hline $\mathrm{EE}$ & 81 & 83 & 86 & 86 & 87 & $\mathrm{Y}=85,0$ & - \\
\hline
\end{tabular}

\section{Conclusões}

As dietas a base de farelo de melancia forrageira e feno de guandu apresentam digestibilidades satisfatórias e proporcionam consumos de matéria seca adequados para atender as exigências nutricionais de ovinos em crescimento.

\section{Literatura citada}

CÂNDIDO, M.J.D. REUNIÃO ANUAL DA SOCIEDADE BRASILEIRA DE ZOOTECNIA. Produção animal no Semi-árido Brasileiro., 2005.

GOMIDE, C. A. M.; RANGEL J. H. A.; MUNIZ, E. N. et al. Alternativas alimentares para ruminantes. Aracajú, SE: EMBRAPA-TABULEIROS COSTEIROS, 2006. 206p. Il.

GONZAGA NETO, S.; BATISTA, A. M. V.; CARVALHO, F. F.R.; MARTINEZ, R. L. V.; BARBOSA, J. E. A. S.; SILVA, E. O. Composição bromatológica, consumo e digestibilidade in vivo de dietas com diferentes níveis de feno de catingueira (Caesalpinea bracteosa), fornecidas para ovinos Morada Nova. Rev. Bras. Zootec., v.30, n.2, p. $553-562,2001$.

KRISHNAMOORTHY U.; SOLLER, H.; STEINGAS, S.; MENKE, K.H. Energy And protein evaluation of tropical feedstuffs for whole tract and ruminal digestion by chemical analyses and rumen inoculum studies in vitro. Animal Feed Science and Technology , v. 52, p. 177- 188, 1995.

NATIONAL RESEARCH COUNCIL - NRC. Nutrient requeriments of Dairy Cattle. Washington, DC.: National Academy of Sciences, 1985.

WOODWARD, A.; REED, J. D. Intake and digestibility for sheep and goats consuming supplementary Acacia brevispica e Sesbania sesban. Animal Feed Science and Technology., v.56, p.207-216, 1995. 